\title{
Higher relatedness within groups due to variable subadult dispersal in a rainforest skink, Gnypetoscincus queenslandiae
}

\author{
JOANNA SUMNER \\ School of Biological Sciences, University of Wollongong, NSW 4522, Australia
}

\begin{abstract}
Field observations of groups of the prickly forest skink, Gnypetoscincus queenslandiae (Reptilia: Scincidae), from north-eastern Australia, that consist of different sized individuals under the same log have generated speculation about the social structure and dispersal patterns of this species. A total of 411 skinks were sampled from 12 rainforest sites on the Atherton Tableland in the Wet Tropics of north-eastern Australia. Relatedness statistics calculated using nine microsatellite DNA loci showed that prickly forest skinks are significantly more related to animals within their own group than to those in other groups, and there is a significantly greater relatedness between subadults less than 2 years old and adults within the same group. This relationship was no longer apparent between individuals estimated to be 2 to 3 years old and adults in the same group. Thirty per cent of individuals estimated to be less than 2 years old were likely to be the offspring of an adult under the same log, whereas only $7 \%$ of individuals between 2 and 3 years old were. Using mark-recapture techniques, movement distances between 0 and $94 \mathrm{~m}$ were recorded, with an average movement distance of $12.8 \mathrm{~m}$, or $1.5 \mathrm{~m}$ per month between captures. Movements of $0-5 \mathrm{~m}$ were the most frequent for all ages and sexes. Subadults tended to move further per month on average than adults, but there was no difference in average movement between adult males and females. Thus I found little evidence to support a hypothesis of complex social structuring in prickly forest skinks. Rather, groups of lizards under logs appear to be a result of high, but variable, dispersal of subadults in their first 2 years.
\end{abstract}

Key words: dispersal, Gnypetoscincus queenslandiae, microsatellite, relatedness, skink.

\section{INTRODUCTION}

Dispersal is a trait common to most animals at some point in their life cycle, either from their birth site or between breeding events as adults. In the literature, dispersal has been described as a mechanism to avoid the costs of inbreeding and competition among juveniles for resources, with the dispersing sex largely determined by the mating system (Greenwood 1980; Clobert et al. 2001). A small body of work is now building on dispersal in reptiles (Clobert et al. 1994; Doughty et al. 1994; Massot \& Clobert 1995, 2000; Olsson \& Shine 2003). Reptiles show a diversity of dispersal patterns, with explanations for dispersal ranging from sex (Olsson \& Shine 2003), year (Doughty et al. 1994) and age (Olsson et al. 1996) to humidity (Massot et al. 2002). With no clear patterns on which to base hypotheses concerning dispersal patterns in lizard species, and the importance of dispersal in maintaining genetically diverse populations in the face of habitat fragmentation, knowledge of dispersal patterns in a species

Present address: School of Botany and Zoology, Australian National University, Canberra, ACT 0200, Australia (Email: joanna.sumner@anu.edu.au)

Accepted for publication October 2005. can be extremely important in most ecological systems.

Recent studies on lizards have also produced evidence of complex mating strategies (Sinervo \& Lively 1996; Zamudio \& Sinervo 2000; Chapple 2003), social and sexual monogamy (Bull 1988; Bull et al. 1998), parental care (Shine 1988), kin recognition (Bull et al. 1994; Main \& Bull 1996), family groups (Gardner et al. 2001; Stow et al. 2001; Chapple 2003) including 'nuclear families' (O'Connor \& Shine 2003) and other stable aggregations (Vitt \& Zani 1996). It has been suggested that sociality and parental care in reptiles evolved in response to a limited availability of preferred retreat sites (Gardner et al. 2001; Stow et al. 2001; Vitt \& Zani 1996). Sociality is especially common in the family Scincidae, in which a number of species in the Egernia genus are documented to live in groups of highly related individuals (Gardner et al. 2001; Stow et al. 2001; Chapple 2003; O'Connor \& Shine 2003), and are socially and sexually monogamous (Gardner et al. 2002; O'Connor \& Shine 2003).

The prickly forest skink (Gnypetoscincus queenslandiae; Reptilia: Scincidae) is a rainforest endemic skink from the Wet Tropics of north-eastern Australia. It is common inside and under moist rotting logs on the forest floor on which it relies for cover and prey (Cogger 2000). Dispersal in G. queenslandiae is extremely 
restricted, evidence for which is seen in the occurrence of a genetic isolation by distance pattern in an area of just 3 ha (Sumner et al. 2001). There is also evidence for sex-biased dispersal in this species, with males as the dispersing sex, obtained from relatedness estimates between adults (Sumner 2005). Field observations indicate that groups of different sized prickly forest skinks are often found under the same log, begging the question of whether these skinks are an additional example of a social lizard.

Molecular methods utilizing highly variable loci, such as microsatellite DNA, are ideal for calculating relatedness between individuals with unknown ancestors and hence for assessing the occurrence of mechanisms such as sex-biased dispersal (Queller et al. 1993; Luikart \& England 1999; Sunnucks 2000). Molecular methods also allow one to gain information on dispersal that may not be possible with field-based mark-recapture methods, especially in species like the prickly forest skink which has low dispersal and is not easily seen or captured without disturbing its log habitat (Sumner et al. 2001).

The specific aims of this study were to determine whether prickly forest skink aggregations are random groupings owing to a limited number of available log retreat sites, or consist of related groups of lizards, and to investigate whether there is evidence for dispersal by a particular sex or at a specific age class.

\section{METHODS}

\section{Study species}

Prickly forest skinks are a rainforest obligate species, endemic to the Wet Tropics of Queensland. They mature at approximately $65 \mathrm{~mm}$ snout to vent length (SVL), with females giving birth to one to five live young between January and April (Cunningham 1993;
Sumner et al. 2001). They are moderately long-lived, with an estimated generation time of 6.5 years and a maximum age of approximately 10 years (Cunningham 1993; Sumner et al. 2001). Dispersal rates for prickly forest skinks, estimated from individual markrecapture data, indicate higher average movement for subadult prickly skinks than adults, with dispersal estimated to be highest in the first 2 years, then decreasing substantially at maturity ( $>65 \mathrm{~mm}$ SVL; Sumner et al. 2001).

\section{Field work}

Between 18 and 42 lizards were sampled from each of 11 rainforest sites on the Atherton Tableland in the Wet Tropics of north-eastern Queensland during a single field trip in January 2000, with 93 lizards from an additional site (Massey Creek) collected in November 1998 (Table 1). A total of 411 prickly forest skinks were captured and genotyped, of which 126 were adult females, 90 were adult males, 190 were subadults and five were of unknown age or sex. Sites were from within a $10 \times 15-\mathrm{km}$ area, and all sites were at least $1 \mathrm{~km}$ apart (see map in Sumner et al. 2004). These samples were all taken pre-parturition (births occurred between January and March at these sites), so all subadults were at least 8 months old. Skinks were hand captured, and the SVL, sex, and whether an individual was found as part of a group were recorded. A tail tip was taken from each individual and fresh frozen on dry-ice for later extraction of DNA. Groups were defined as all individuals caught under or within a single rotting $\log$, and individuals in a group were usually less than $150 \mathrm{~cm}$ apart. Individuals of less than $65 \mathrm{~mm}$ SVL could not be sexed reliably in the field, and were recorded as subadults. Subadults were further divided into those that were $55 \mathrm{~mm} \mathrm{SVL}$ or less, the

Table 1. Sites sampled, the number of individuals genotyped (No. of sampled), latitude and longitude of each site, site type, and the fragment area in hectares (ha) as generated by remotely sensed mapping

\begin{tabular}{|c|c|c|c|c|c|}
\hline Site & No. of sampled & Latitude & Longitude & Site type & Fragment area (ha) \\
\hline Souita Falls & 25 & 145.39 & 17.34 & Fragment & 2.00 \\
\hline Maalan Road & 42 & 145.34 & 17.435 & Fragment & 2.46 \\
\hline Waltham & 27 & 145.37 & 17.33 & Fragment & 2.64 \\
\hline Pat Daley Pk & 18 & 145.37 & 17.32 & Fragment & 5.96 \\
\hline Trantor & 29 & 145.37 & 17.33 & Fragment & 24.19 \\
\hline Whiteing Road & 30 & 145.36 & 17.34 & Fragment & 36.31 \\
\hline Millaa Millaa Falls & 27 & 145.37 & 17.3 & Fragment & 65.06 \\
\hline Brotherton & 28 & 145.34 & 17.34 & Continuous & - \\
\hline Cross-eye & 30 & 145.38 & 17.35 & Continuous & - \\
\hline Mt.Father Clancy & 32 & 145.38 & 17.36 & Continuous & - \\
\hline Reynolds & 28 & 145.34 & 17.33 & Continuous & - \\
\hline Massey Ck & 94 & 145.34 & 17.37 & Continuous & - \\
\hline
\end{tabular}


estimated size of individuals at 2 years of age, and into individuals of $56-63 \mathrm{~mm}$ SVL, the estimated size of animals aged between 2 and 3 years. Prickly skinks are thought to start reproduction in their third year (Sumner et al. 2001), so comparison of the 3- to 4-year age class with other age classes was not carried out as this age class was likely to contain a mixture of immature and mature individuals. Age estimates were calculated from growth rates detailed in Sumner et al. (2001).

To determine distances moved by individuals over time, a mark-recapture study was carried out at Massey Creek from November 1995 to November 1998. During each of seven biannual trips, a complete search was made of a 3-ha area within the forest that was divided into a grid of $4825 \times 25$-m squares. Each animal caught was marked using an individual combination of toe clips, and the capture location within the site was recorded to the nearest $5 \mathrm{~m}$ (see Sumner et al. 2001 for details). The distance moved by individuals captured was calculated as the straight-line distance between capture points. Estimates of movement per month were calculated by dividing the movement distance by the number of months since the previous capture. Significance of comparisons of movement distances among males, females and subadults was calculated using ANCOVA, with time as the covariate.

\section{Genetic data}

DNA was extracted using a standard phenol-chloroform extraction procedure (Sambrook et al. 1989) on the fresh frozen lizard tails. Nine microsatellite loci were amplified by polymerase chain reaction as in Sumner et al. (2001). Primer pairs that were used were: GQ10/11F GQ16/17F2, GQ18/19F, GQ20/ 21F, GQ24F/25, GQ36/37F, GQ38B/39F, GQ42B/ $43 \mathrm{~F}$ and $\mathrm{EA} 1 \mathrm{~F} / 2 \mathrm{~B}$. PCR products were resolved on an Applied Biosystems model 373 DNA sequencer and analysed using the manufacturer's proprietary GENESCAN and GENOTYPER software.

\section{Measuring relatedness}

The average relatedness among individuals was estimated using the programme RELATEDNESS 5.07 (Goodnight \& Queller 1998), which performs as well as other marker-based relatedness programmes (Van de Casteele et al. 2001). The programme calculates an index of relatedness $(R)$ between individuals or demographically defined groups, using a regressionbased measure of relatedness calibrated by the frequency of alleles and number of individuals in the population. An unbiased estimate of relatedness within subsamples of a population requires a large reference population of many unrelated individuals, whose genetic difference is due to being unrelated only, not due to being sampled from divergent isolated populations. In this study each site was analysed as a separate 'deme' as significant differences in allele frequencies occurred among sites (Sumner et al. 2004). Subadults were excluded from the reference population database for each site to avoid biasing the estimates with a high proportion of related animals. The Queller and Goodnight (1989) index of $R$, between pairs of individuals, may vary between -1 and +1 , but with the proper reference population it would be expected to vary between 0 and 1 . Stochastic variation in $R$ is expected, and, in particular, when either of the individuals possesses a rare allele, a negative $R$-value may be expected (de Ruiter \& Geffin 1998). Standard errors of $R$ estimates were obtained by jack-knifing over the nine loci and also over the 12 sites (Queller \& Goodnight 1989). Values were jack-knifed over loci, preferentially, as the relationship between animals in the samples was not known, but the loci appeared to be independent and not sex-linked (Sumner et al. 2001, 2004). Only the results of jack-knifing over loci are reported, unless the results differed considerably when jack-knifing over sites.

\section{Relatedness within groups}

To test the hypothesis that the groups consist of highly related individuals, $R$ within groups was first estimated by calculating the average pairwise relatedness of each individual to all others within its group and comparing this with pairwise relatedness between each individual and all those in other groups. If groups consist of related individuals in 'family groups', the adults in the group are likely to be less related than subadults to each other and less related than subadults to the adults in the group. I compared $R$ between adults within groups with adults in other groups, between all subadults within groups with subadults in other groups, and between adults and all subadults within groups with adults and subadults in other groups. This was then repeated for subadults estimated to be less than 2 years and for subadults estimated to be 2-3 years old.

The relationship between individuals within groups was also tested directly using the programme KINSHIP 1.2 (Queller \& Goodnight 1989). In this programme a specified hypothesis about the pedigree relationship between pairs of individuals is tested using the population allele frequencies and the genotypes of the two individuals under consideration to calculate the likelihood that this genotype combination could have been produced by the relationship specified. 


\section{RESULTS}

\section{Movement data at Massey Creek}

A total of 513 individuals were captured over the seven trips; 156 individuals were later recaptured at least once (see Sumner et al. 2001 for details). Individuals were first recaptured between 3 and 35 months after their initial capture (Fig. 1). Any additional recaptures were not used in the following calculations. In that time, movement distances between 0 and $77 \mathrm{~m}$ were recorded, with an average movement distance of $12.8 \mathrm{~m}(\mathrm{SE}=1.61)$, or $1.5 \mathrm{~m}$ per month $(\mathrm{SE}=0.28)$ between captures. Movements of $0-5 \mathrm{~m}$ were the most frequent for all ages and sexes (Fig. 2). No adult male was found to move further than $20 \mathrm{~m}$. An ANCOVA between adults and subadults, with distance as the dependent variable and time (months) as the covariate, showed a significant difference in movement patterns over time (average movement adults $=0.76 \mathrm{~m}$; subadult $=1.88 \mathrm{~m} ; F=$ 6.27; d.f. $=1,123 ; P=0.014)$. No significant difference in movement over time was found between adult females and males (average movement females = $0.86 \mathrm{~m} ; \quad$ males $=0.69 \mathrm{~m} ; \quad F=0.19 ; \quad$ d.f. $=1, \quad 26$; $P=0.89$ ).

Looking briefly at individual movements to give examples of the movement patterns recorded in this species, three individuals (two females and a male) were recaptured four times, and a fourth individual (female) captured five times. These recaptures spanned 15-25 months, and in all but one case the individuals were recaptured less than $7 \mathrm{~m}$ from the last capture point. The exception was the fifth capture of a female, which had moved $40 \mathrm{~m}$ after spending the previous 15 months within a $5 \mathrm{~m}^{2}$ area. Seven individuals were captured under the same log 8-20 months after their initial capture.

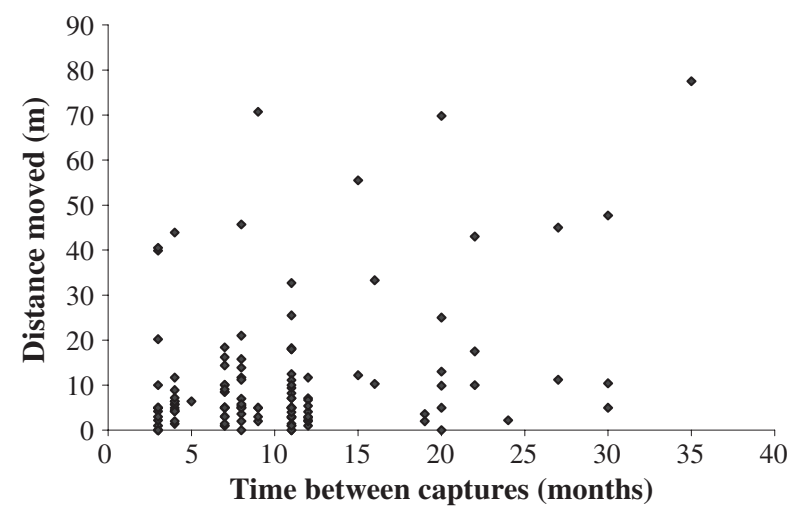

Fig. 1. Distance moved between initial capture and recapture of prickly forest skinks at Massey Creek.

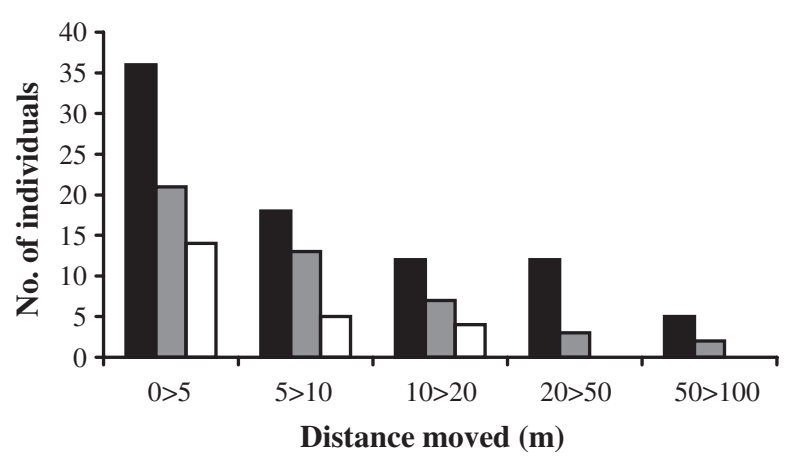

Fig. 2. Distance moved by individuals between captures at Massey Creek. Animals are grouped as ( $\square$ ) subadult, ( $\square$ ) female or $(\square)$ male. Individuals captured first as subadults ( $<65 \mathrm{~mm}$ snout to vent length), then later as adults, are scored as subadults.

Table 2. The number of groups of each size (1-9 individuals), percentage of groups at each group size and Relatedness $(R)$ within groups of prickly forest skinks

\begin{tabular}{lccc}
\hline Group size & No. of groups & \% of groups & Average $R$ \\
\hline 1 & 249 & - & -0.032 \\
2 & 29 & 51.7 & 0.097 \\
3 & 16 & 28.6 & 0.016 \\
4 & 6 & 10.7 & -0.013 \\
5 & 3 & 5.4 & -0.022 \\
6 & 0 & 0 & - \\
7 & 0 & 0 & - \\
8 & 1 & 1.8 & -0.032 \\
9 & 1 & 1.8 & 0.009 \\
\hline
\end{tabular}

Relatedness for singletons was calculated pairwise among all individuals.

\section{Group size and composition}

Of the 411 prickly forest skinks captured for the group size study, 162 individuals (39.4\%) were in groups, ranging in size from 2 to 9 (Table 2). The age and sex of individuals in groups varied, with groups most commonly consisting of a female and a subadult, two subadults or a male and a subadult. No groups consisted of males only, although multiple males were found in some of the larger groups.

\section{Genetic analysis}

Complete genotypes were obtained for 362 individuals and partial genotypes for the remaining 49. The total number of alleles per locus ranged from 5 to 28, with an average of 19.6 alleles per locus across all sites (Sumner et al. 2004). Sumner et al. (2001, 2004) found no evidence of sex-linkage or genotypic disequilibrium for these loci, and all loci appeared to be in 
Hardy-Weinberg equilibrium. There was no strong evidence of null alleles at any locus (Sumner et al. 2001, 2004).

\section{Relatedness within groups}

Average pairwise $R$ among all 411 prickly skinks across all sites was $-0.031(\mathrm{SE}=0.0004)$. Pairwise relatedness between all individuals that were captured in a group $(R=-0.021 ; \mathrm{SE}=0.008)$ was significantly higher than between all individuals that were not grouped $(R=-0.032 ; \mathrm{SE}=0.005 ; P=0.003)$. Average relatedness values within groups ranged from $R=-0.246$ for a group of two females up to $R=0.637$ for a subadult and an individual for which the age and sex were unknown. There was no relationship between group size and relatedness $(F=2.06 ; P=0.22$; d.f. = 1, 52; Table 2).

Individuals were more related to others within their own group ( $R=0.031$; $\mathrm{SE}=0.016)$ than to individuals in other groups $(R=-0.029 ; \mathrm{SE}=0.008$; $P<0.001)$. Adults did not differ significantly in their relatedness to other adults within their group compared with that to other adults in other groups $(P=$ 0.54; Table 3). Subadults were no more related to others within their own group than to individuals in other groups $(P=0.282)$, indicating that subadults in the same group were not necessarily siblings. Subadults were found to be significantly more related to adults in own same group than to other adults in different groups $(P<0.001)$.

Subadults less than 2 years old were significantly more related to adults within the same group than to adults in other groups $(P<0.001$; Table 3$)$. However, subadults between 2 and 3 years of age were no more related to adults within their group than to adults in different groups $(P=0.676)$.

To determine whether subadults were the offspring of adults within their same group I tested pairwise combinations of individuals under the hypothesis of one individual being the parent of the other using likelihood methods. There were 45 possible parent/ offspring pairs for which the subadult was less than 2 years old, and 15 pairs for which the subadult was between 2 and 3 years. Thirteen individuals less than 2 years old were found to have a significant $(<0.05)$ likelihood of being the offspring of an adult under the same $\log (28.9 \%$ of pairs). Only one individual between 2 and 3 years old was likely to be the offspring of an adult in the same group (6.7\% of pairs).

\section{DISCUSSION}

This study found a low level of passive aggregation in the prickly forest skink, apparently as a consequence of variable subadult dispersal. A significantly higher level of within-group relatedness of individuals appears to be due to the higher average relatedness between adults and subadults less than 2 years of age. This relationship no longer holds for subadults over 2 years of age, with no difference in relatedness values within groups than among individuals in different groups at this age. Direct assessment of parentage supports the higher incidence of parent/offspring pairs in groups with subadults less than 2 years old compared with groups with subadults between 2 and 3 years old. The unexpectedly low relatedness between subadults within the same group may be due to a large number of comparisons between subadults from different cohorts (pre-dispersal and post-dispersal individuals). Further analysis of within cohort $R$ may clarify this, but small sample size prohibited this in the current study.

The change in relatedness with age agrees with data on the dispersal rates of prickly forest skinks in different age classes (Sumner et al. 2001). Prickly skinks showed high dispersal in their first 2 years (approximately $33 \mathrm{~m} \mathrm{month}^{-1}$ ), reduced dispersal in the third year $\left(23 \mathrm{~m} \mathrm{month}^{-1}\right)$ and were sedentary by the sixth year. Movement data recorded in this study indicate that despite this high dispersal rate in the first few years most subadults moved only short distances $\left(<5 \mathrm{~m} \mathrm{month}^{-1}\right)$. The variance in subadult movement may explain the findings of both a high dispersal rate, and a high level of relatedness between subadults and adults. The high dispersal rate in subadults should still lead to low levels of relatedness among individuals in a group, and this study indicates that by their third

Table 3. Average relatedness $(R)$ estimates for comparisons between adults (A), all subadults (SA), subadults less than 2 years old ( $<2$ years) and subadults between 2 and 3 years old (2-3 years), within the same group (SG), or in other groups (OG). Standard error is in brackets following relatedness estimate

\begin{tabular}{lccrr}
\hline Category & A & SA & SA (<2 years $)$ & SA $(2-3$ years $)$ \\
\hline A (SG) & $-0.024(0.025)$ & $0.054(0.024)$ & $0.080(0.023)$ & $-0.038(0.052)$ \\
A (OG) & $-0.017(0.016)$ & $0.001(0.018)$ & $-0.045(0.016)$ & $-0.046(0.016)$ \\
SA (SG) & - & $0.001(0.033)$ & - & - \\
SA (OG) & - & $-0.013(0.016)$ & - & - \\
\hline
\end{tabular}


year the relatedness levels of subadults and adults within groups under a single log have reached a level similar to that found among the remainder of the population. This occurs at approximately the same time at which dispersal rates in subadults were found to decrease (Sumner et al. 2001). Thus, dispersal by subadults appears to be high (but variable) for the first 2 years, with the high average $R$ suggesting deferral of dispersal by some subadults. Sampling immediately following parturition may further elucidate the extent of dispersal in the first 2 years by enabling a split of the youngest age class studied here into years 1 and 2 . Determining the sex of subadults may also help clarify dispersal patterns, as variation may be explained by differential dispersal between sexes, evidence of which has been found in adults (Sumner 2005).

Low movement recorded in adults in this study and Sumner et al. (2001) suggests that once the dispersal phase is over, prickly skinks remain relatively sedentary. Further research may indicate whether prickly forest skinks exhibit 'territoriality' as suggested by the low adult dispersal and the almost complete lack of groups that include multiple adult males. Movement by adult females appears to be more variable than for adult males, with males moving a maximum of $20 \mathrm{~m}$ (Fig. 2), whereas adult females were found to move over $50 \mathrm{~m}$, possibly indicating female dispersal between breeding events (Olsson \& Shine 2003).

Parental care is relatively rare in reptiles (Shine 1988). Gardner et al. (2001) reported little evidence of parental provisioning in Egernia stokesii, but suggested that parental vigilance, access to parental food and refuge resources, and the ability to inherit the natal crevice are important benefits of family group living. In the sleepy lizard (Tiliqua rugosa), juveniles do not disperse out of the home range of their mother in the first year (Bull \& Baghurst 1998) but again there is no evidence of parental care during that time. There is no evidence for parental care in prickly forest skinks, although when captured, neonates will 'cling' to adults (J. Sumner pers. obs. 1998), a similar behaviour to that observed in the highly social skink Egernia saxatilis (O'Connor \& Shine 2003). Deferral of dispersal by some subadults may therefore be due, in part, to the benefits of parental food and refuge resources (Massot \& Clobert 1995).

The higher $R$ between individuals found in a group compared with that found between ungrouped individuals is likely to be due to the higher probability of sampling related individuals in groups. However, a significant isolation by distance pattern was found in prickly forest skinks sampled across a 3-ha site (Sumner et al. 2001), so it might be argued that it is due to the smaller geographical area encompassed by those individuals in a group compared with all individuals captured at a site. The isolation by distance pattern may also be a confounding factor in the comparison of the relatedness of individuals within groups to individuals in different groups. Individuals might therefore be less related to individuals in other groups than to those in their own group owing to the geographical distance between groups, rather than owing to social structuring within groups. Comparisons between adult skinks within groups and those in different groups indicated no significant difference in relatedness. Relatedness was in fact lower within groups than between groups. Isolation by distance did not appear to affect comparisons between subadults either (although relatedness was higher within than between groups in this case). Ecological factors thus appear to be more important in determining relatedness levels in groups, with lower relatedness within groups between adults perhaps a reflection of kin-avoidance (Bull \& Cooper 1999; Gardner et al. 2001), and higher relatedness between subadults within groups a result of deferred dispersal.

Two recent studies have investigated relatedness values and dispersal in skinks, both finding highly related individuals living together in groups. Gardner et al. (2001) compared relatedness values in Egernia stokesii between highly related individuals in stable aggregations in rock outcrops. The average relatedness among all skinks in their study $(-0.0106)$ was higher than at all sites studied here, however, the skinks in that study were sampled within a 1-ha site, smaller than all the sites sampled here. Gardner et al. (2001) found that skinks were more closely related to individuals geographically close to them at all levels of population age structure, and for both sexes. Average relatedness within groups was $R=0.1662$ (Gardner et al. 2001). Stow et al. (2001) found within group $R$-values (mean \pm SD) of $0.253 \pm 0.274$ in cleared sites and $0.264 \pm 0.247$ in reserve sites. Both these studies found higher within group relatedness values than were found here for prickly forest skinks $(R=0.030)$, suggesting much looser associations of individuals in prickly forest skink groups than in the groups of E. stokesii and Egernia cunninghami. A number of the microsatellites used in this paper had very high numbers of alleles (up to 28 alleles, with an average of 19.6; Sumner et al. 2004), so the occurrence of rare alleles in each population may be quite high and could result in underestimation of relatedness values. Considering the substantial difference in the $R$-values recorded, as well as the impermanence of the rotting logs inhabited by prickly forest skinks compared with the rock crevices inhabited by the Egernia species, the smaller $R$ value in prickly forest skinks is not surprising.

In conclusion, little evidence was found to support a hypothesis of complex social structure in prickly forest skinks. Rather, groups of lizards under logs appear to be loose aggregations of individuals, with higher relatedness a result of variable dispersal of subadults up to 2 years of age. Dispersal patterns appear 
to be complex despite the limited distances moved in a lifetime. In order to understand and explain dispersal patterns in prickly forest skinks better it would be important to identify differential dispersal between subadult males and subadult females to determine to what extent sex-biased dispersal is driving the observed pattern.

\section{ACKNOWLEDGEMENTS}

I would like to thank John Winter and Helen Myles from the Massey Creek Research Station for their hospitality and cooperation during the research. I would like to thank Craig Moritz, Tim Jessop, Conrad Hoskin, David Paetkau and all the volunteers for unlimited enthusiasm and support in various parts of this research. Many thanks to Kelly Zamudio for comments on an earlier draft of this paper. This research was completed as part of my PhD dissertation, supported by an Australian Postgraduate Award and the Rainforest Cooperative Research Centre.

\section{REFERENCES}

Bull C. M. (1988) Mate fidelity in an Australian lizard Trachydosaurus rugosus. Behav. Ecol. Sociobiol. 23, 45-9.

Bull C. M. \& Baghurst B. C. (1998) Home range overlap of mothers and their offspring in the sleepy lizard, Tiliqua rugosa. Aust. F. Zool. 47, 125-32.

Bull C. M. \& Cooper S. J. B. (1999) Relatedness and avoidance of inbreeding in the lizard, Tiliqua rugosa. Behav. Ecol. Sociobiol. 46, 367-72.

Bull C. M., Doherty M., Schulze L. R. \& Pamula Y. (1994) Recognition of offspring by females of the Australian skink, Tiliqua rugosa. F. Herpetol. 28, 117-20.

Bull C. M., Cooper S. J. B. \& Baghurst B. C. (1998) Social monogamy and extra-pair fertilization in an Australian lizard, Tiliqua rugosa. Behav. Ecol. Sociobiol. 44, 63-72.

Chapple D. (2003) The evolution of complex sociality in reptiles: a review of ecology, life-history and behavior in the Australian scincid genus Egernia. Herpetol. Monogr. 17, 146-80.

Clobert J., Massot M., Lecomte J., Sorci G., de Fraipont M. \& Barbault R. (1994) Determinants of dispersal behaviour: the common lizard as a case study. In: Lizard Ecology: Historical and Experimental Perspectives (eds L. Vitt \& E. Pianka) pp. 183-206. Princeton University Press, Princeton.

Clobert J., Danchin E., Dhondt A. A. \& Nichols J. D. (2001) Dispersal. Oxford University Press, Oxford.

Cogger H. G. (2000) Reptiles and Amphibians of Australia, 6th edn. Reed Books, Sydney.

Cunningham M. (1993) Reproductive biology of the prickly forest skink, Gnypetoscincus queenslandiae, an endemic species from northern Queensland. Mem. Qld Mus. 34, 131-8.

de Ruiter J. R. \& Geffin E. (1998) Relatedness of matrilines, dispersing males and social groups in long-tailed macaques (Macaca fascicularis). Proc. Roy. Soc. London B $265,79-87$.
Doughty P., Sinervo B. \& Burghardt G. M. (1994) Sex-biased dispersal in a polygynous lizard, Uta stansburiana. Anim. Behav. 47, 227-9.

Gardner M. G., Bull C. M., Cooper J. B. \& Duffield G. A. (2001) Genetic evidence for a family structure in stable social aggregations of the Australian lizard Egernia stokesii. Mol. Ecol. 10, 175-83.

Gardner M. G., Bull C. M. \& Cooper S. J. B. (2002) High levels of genetic monogamy in the group-living Australian lizard Egernia stokesii. Mol. Ecol. 11, 1787-94.

Goodnight K. F. \& Queller D. C. (1998) RELATEDNESS 5.08. [Cited $00 \mathrm{Xxxx}$ 0000.] Available from URL: http:// gsoft.smu.edu/gsoft.html.

Greenwood P. J. (1980) Mating systems, philopatry and dispersal in birds and animals. Anim. Behav. 28, 1140-62.

Luikart G. \& England P. R. (1999) Statistical analysis of microsatellite DNA data. Tree 14, 253-6.

Main A. R. \& Bull C. M. (1996) Mother-offspring recognition in two Australian lizards, Tiliqua rugosa and Egernia stokesii. Anim. Behav. 52, 193-200.

Massot M. \& Clobert J. (1995) Influence of maternal food availability on offspring dispersal. Behav. Ecol. Sociobiol. 37, 413-18.

Massot M. \& Clobert J. (2000) Processes at the origin of similarities in dispersal behaviour among siblings. F. Evol. Biol. 13, 707-19.

Massot M., Clobert J., Lorenzon P. \& Rossi J. M. (2002) Condition-dependent dispersal and ontogeny of the dispersal behaviour: an experimental approach. F. Anim. Ecol. 71, 253-61.

O'Connor D. \& Shine R. (2003) Lizards in 'nuclear families': a novel reptilian social system in Egernia saxatilis (Scincidae). Mol. Ecol. 12, 743-52.

Olsson M. \& Shine R. (2003) Female-biased natal and breeding dispersal in an alpine lizard, Niveoscincus microlepidotus. Biol. 7. Linn. Soc. 79, 277-83.

Olsson M., Gullberg A. \& Tegelstrom H. (1996) Malformed offspring, sibling matings, and selection against inbreeding in the sand lizard (Lacerta agilis). F. Evol. Biol. 9, 229-42.

Queller D. C. \& Goodnight K. F. (1989) Estimating relatedness using genetic markers. Evolution 43, 258-75.

Queller D. C., Strassmann J. E. \& Hughes C. R. (1993) Microsatellites and kinship. Tree 86, 285-8.

Sambrook J., Fritsch E. F. \& Maniatis T. (1989) Molecular Cloning: a Laboratory Manual, 2nd edn. Cold Spring Harbor Laboratory Press, New York.

Shine R. (1988) Parental care in reptiles. In: Biology of the Reptilia (eds C. Gans \& R. B. Huey) pp. 276-329. Alan R. Liss, Inc., New York.

Sinervo B. \& Lively C. M. (1996) The rock-paper-scissors game and the evolution of alternative male strategies. Nature 380, 240-3.

Stow A. J., Sunnucks P., Briscoe D. A. \& Gardner M. G. (2001) The impact of habitat fragmentation on dispersal of Cunningham's skink (Egernia Cunninghami): evidence from allelic and genotypic analysis of microsatellites. Mol. Ecol. $10,867-78$.

Sumner J. (2005) Decreased relatedness between male prickly forest skinks (Gnypetoscincus queenslandiae) in habitat fragments. Cons. Genet. 6, 333-40.

Sumner J., Rousset F., Estoup A. \& Moritz C. (2001) 'Neighbourhood size', dispersal and density estimates in the prickly forest skink (Gnypetoscincus queenslandiae) using individual genetic and demographic methods. Mol. Ecol. 10, 1917-27. 
Sumner J., Jessop T., Paetkau D. \& Moritz C. (2004) Limited effect of anthropogenic habitat fragmentation on molecular diversity in a rainforest endemic skink, Gnypetoscincus queenslandiae. Mol. Ecol. 13, 259-69.

Sunnucks P. (2000) Efficient genetic markers for population biology: single locus, co-dominant, yielding genealogies. Tree 15, 199-203.

Van de Casteele T., Galbusera P. \& Matthysen E. (2001) A comparison of microsatellite-based pairwise relatedness estimators. Mol. Ecol. 10, 1539-49.

Vitt L. J. \& Zani P. A. (1996) Ecology of the elusive tropical lizard Tropidurus [= Uracentron] flaviceps (Tropiduridae) in lowland rain forest of Ecuador. Herpetologica 52, 121-32.

Zamudio K. R. \& Sinervo B. (2000) Polygyny, mate-guarding, and posthumous fertilization as alternative male mating strategies. Proc. Nat. Acad. Sci. USA 97, 14427-32. 